\title{
Differential Cone Pathway Influence on Intrinsically Photosensitive Retinal Ganglion Cell Subtypes
}

\author{
Tiffany M. Schmidt and Paulo Kofuji \\ Department of Neuroscience, University of Minnesota, Minneapolis, Minnesota 55455
}

A small subset of ganglion cells in the mammalian retina express the photopigment melanopsin and are intrinsically photosensitive (ipRGCs). These cells are the primary conduits through which photic information is relayed to non-image-forming visual centers that mediate behaviors such as the pupillary light reflex and circadian entrainment. M1 and M2 cells comprise distinct morphological subpopulations of ipRGC, and possess physiological diversity in their intrinsic membrane properties and intrinsic light responses. Additionally, evidence now indicates that all ipRGCs receive photic information from rods/cones via synaptic signaling. It has recently been reported that Off-stratifying M1 cells paradoxically receive input from the On pathway within the Off sublamina of the inner plexiform layer. The purpose of the current study was to examine the functional consequences of cone pathway signaling to M1 and M2 cells. Using pharmacological tools and single-cell recordings of synaptic responses in wild-type and melanopsin-null mice, we found that the On pathway forms the primary excitatory synaptic input to both M1 and M2 cells. This input was much more influential in shaping the light-evoked responses and resting membrane properties of $\mathrm{M} 2$ cells than $\mathrm{M} 1$ cells. These findings indicate a surprising differential reliance upon cone-mediated phototransduction by ipRGC subpopulations. These findings also suggest that ipRGC subtypes signal diverse photic information to various non-image-forming visual centers.

\section{Introduction}

In mammals, environmental irradiance information is conveyed to non-image-forming centers in the brain primarily by a small population of retinal ganglion cells (RGCs) that express the photopigment melanopsin, rendering them intrinsically photosensitive (ipRGCs) (Berson et al., 2002; Hattar et al., 2002). A growing body of evidence indicates that ipRGCs also receive and integrate photic information from rods and cones via synaptic influences (Dacey et al., 2005; Wong et al., 2007; Göz et al., 2008; Güler et al., 2008; Hatori et al., 2008; Schmidt et al., 2008; Pickard et al., 2009). ipRGCs project to brain areas involved in non-imageforming vision such as the olivary pretectal nucleus (OPN), which drives the pupillary light reflex, and the suprachiasmatic nucleus of the hypothalamus (SCN) which houses the main circadian pacemaker in the brain (Gooley et al., 2001, 2003; Hattar et al., 2002, 2006; Hannibal and Fahrenkrug, 2004; Baver et al., 2008).

Segregation of RGC dendrites in the retina is correlated with functional roles (Wässle, 2004). RGCs stratifying in the inner half of the inner plexiform layer (IPL) signal light increases via synaptic inputs from On bipolar cells (BCs). RGCs stratifying in the outer half of the IPL signal light decrements via synaptic inputs from Off BCs. ipRGCs can be divided into distinct subpopulations with distinct dendritic arborization within the IPL: M1 cells

Received July 14, 2010; revised Sept. 17, 2010; accepted Sept. 21, 2010.

This work was supported in part by National Institutes of Health Grants R01EY012949, R21-EY018885, and T32 EY0707133. We thank Darwin Hang and Jimmy Petitti for their technical assistance.

Correspondence should be addressed to Paulo Kofuji, Department of Neuroscience, University of Minnesota, 6-145 Jackson Hall, 321 Church St SE, Minneapolis, MN 55455. E-mail: kofuj001@umn.edu.

DOI:10.1523/JNEUROSCI.3656-10.2010

Copyright $\odot 2010$ the authors $\quad 0270-6474 / 10 / 3016262-10 \$ 15.00 / 0$ with dendrites stratifying in the Off sublamina of the IPL, M2,4,5 cells with dendrites stratifying in the On sublamina of the IPL, and bistratified (M3) ipRGCs with dendrites stratifying in both the On and Off sublaminas (Warren et al., 2003; Viney et al., 2007; Baver et al., 2008; Schmidt et al., 2008; Schmidt and Kofuji, 2009; Ecker et al., 2010). Surprisingly, M1 cells have recently been shown to receive synaptic inputs from On BCs within the Off sublamina (Dumitrescu et al., 2009; Hoshi et al., 2009). However, the functional consequences of this atypical On-pathway input for the M1 cell light response have yet to be examined in detail. Furthermore, though On-stratifying M2 cells presumably receive On-pathway input, this has not been confirmed nor have the functional consequences of that input been addressed. M1 and M2 cells have been shown to have marked differences in their morphology, intrinsic membrane properties, and intrinsic light response (Schmidt and Kofuji, 2009), thus synaptic inputs could drastically and differentially affect the output of these physiologically and morphologically distinct ipRGC subtypes.

In the present study, we examined the functional influence of the cone-mediated On pathway in shaping the light-evoked and resting discharge of M1 and M2 cells. We demonstrate that the On pathway forms the primary excitatory synaptic input to both M1 and M2 cells. We find that this input is more influential in shaping the light-evoked and resting properties of M2 cells. M1 cells, however, rely primarily on the intrinsic photoreceptive system to respond to light stimulation. These results support the conclusion that ipRGC subpopulations signal distinct light information to various non-image-forming centers in the brain.

\section{Materials and Methods}

Animals. Recordings were performed on postnatal (P) 25-40 animals from the Opn4-EGFP mouse line described previously (Schmidt et al., 
2008) as well as Opn4-EGFP mice crossed with animals on an Opn4 $4^{-1-}$ background provided by Dr. King-Wai Yau, Johns Hopkins University (Baltimore, MD) (Hattar et al., 2002). Animals were cared for in accordance with guidelines described in Guide for the Care and Use of Laboratory Animals, using protocols approved by the University of Minnesota Institutional Animal Care and Use Committee.

Electrophysiology. Dissections were performed as described previously (Schmidt et al., 2008). Briefly, animals were killed by $\mathrm{CO}_{2}$ asphyxiation and the eyes were enucleated in a dark room with minimal ambient light. Retinas were removed from eyecups under a standard dissection scope and placed in $95 \% \mathrm{O}_{2}-5 \% \mathrm{CO}_{2}$ bicarbonate buffered Ames' solution (Sigma) at room temperature. Before recording, retinas were treated with Ames' solution containing collagenase/hyaluronidase (240 and $1000 \mathrm{U} / \mathrm{ml}$, respectively) at room temperature for $15 \mathrm{~min}$ to remove vitreous. Recordings were performed using an Axon 700B Amplifier (Molecular Devices) with extracellular solution containing 95\% $\mathrm{O}_{2}-$ $5 \% \mathrm{CO}_{2}$ bicarbonate buffered Ames' solution at room temperature, which allowed for stable and robust synaptic responses. Recordings were made with fire-polished borosilicate pipettes (3-7 M $\Omega$; Sutter Instruments). For current-clamp recordings, pipettes were filled with (in $\mathrm{mM}$ ): $125 \mathrm{~K}$-gluconate, $2 \mathrm{CaCl}_{2}, 2 \mathrm{MgCl}_{2}, 10$ EGTA, 10 HEPES, $0.5 \mathrm{NaGTP}$, and $2 \mathrm{Na}_{2} \mathrm{ATP}, \mathrm{pH}$ to 7.2 , with $\mathrm{KOH}$. For voltage-clamp recordings, pipettes were filled with (in mM): 120 Cs methanesulfonate $2 \mathrm{MgCl}_{2}, 5$ HEPES, 5 EGTA, $0.5 \mathrm{CaCl}_{2}, 1 \mathrm{Na}_{2} \mathrm{ATP}, 0.5 \mathrm{NaGTP}, 2 \mathrm{QX} 314$, 5 TEA-Cl, $14-\mathrm{AP}, \mathrm{pH}$ to 7.2 , with $\mathrm{CsOH}$. Intracellular solutions also contained 10-20 $\mu \mathrm{M}$ Alexa Fluor-594 hydrazide (AF-594) (Invitrogen) and following recording dendritic stratification was classified by focusing in the proximal and distal layers of the IPL under epifluorescent illumination at $594 \mathrm{~nm}$ (Schmidt and Kofuji, 2009). Cells monostratifying in the Off sublamina were classified as M1 while cells monostratifying in the On sublamina were classified as M2. It is thus possible that the newly characterized M4 cells were included in our sample of M2 cells (Ecker et al., 2010). If a cell was bistratified or if its stratification could not be clearly identified, that cell was excluded from subsequent analyses. Current and voltage acquisitions were performed with a Digidata 1322 D/A and A/D converter connected to a personal computer running pClamp 10 software (Molecular Devices). Liquid junction potentials between the bath and electrode (14 mV for current-clamp and $13 \mathrm{mV}$ for voltage-clamp solutions) were calculated using the Liquid Junction Potential Calculator (pClamp 10) and were corrected for in all recordings. Retinas were allowed to dark adapt for 5 min before the first light stimulus, and any stimuli were placed $5 \mathrm{~min}$ apart to allow the cell membrane potential to return completely to baseline.

Whole-cell currents were analyzed off-line with Clampfit (Molecular Devices) or Igor Pro 6.0 over a $0.1 \mathrm{~s}$ sliding time window, and membrane potential values were measured from raw traces over a $1 \mathrm{~s}$ sliding time window to maximize the signal-to-noise ratio using Igor Pro 6.0. Resting membrane potential $\left(V_{\mathrm{m}}\right)$ values were calculated by taking the average membrane voltage of the first $10 \mathrm{~s}$ of baseline before any light stimulation. For light response experiments if a cell's resting $V_{\mathrm{m}}$ did not reach $-40 \mathrm{mV}$ negative current was injected to bring the $V_{\mathrm{m}}$ to $\sim-60 \mathrm{mV}$.

Series resistance was noted in all recordings, but uncompensated and only recordings with series resistance of $<30 \mathrm{M} \Omega$ were included for analysis. Cell capacitance $\left(C_{\mathrm{m}}\right)$ and input resistance $\left(R_{\mathrm{N}}\right)$ were calculated from those currents evoked by stepping the cell potential to a $10 \mathrm{mV}$ hyperpolarized value for $20 \mathrm{~ms}$ from a holding potential of $-60 \mathrm{mV}$. Charge $Q$ was estimated by time integration of evoked current during the step voltage. $R_{\mathrm{N}}$ was estimated from the steady-state evoked current during the step voltage. Light responses were defined as the maximum depolarization of the averaged trace during the first $30 \mathrm{~s}$ following light onset. Maximum (Max) current was defined as the maximum inward current measured from the $0.1 \mathrm{~s}$ smoothed trace during the $10 \mathrm{~s}$ light stimulus and total charge was calculated from the area measured during the $10 \mathrm{~s}$ light stimuli. For voltage-clamp experiments, the $10 \mathrm{~s}$ before light stimulation was defined as baseline and set as the 0 current level. Irradiance-response experiments were performed and analyzed as described previously (Schmidt et al., 2008). For kinetics measurements, rise time (RT) was defined as the time for the cell membrane potential or whole-cell current to go from 10 to $90 \%$ of maximum, and decay time
(DT) was defined as the time for recording to decline to $37 \%$ of the maximum value following light offset.

Curve fits for normalized, averaged irradiance-response data were determined by nonlinear regression using Origin 7.0 (MicroCal) according to the logistic dose-response function: $y=A_{2}+\left[\left(A_{1}-A_{2}\right) /(1+\right.$ (IR/ $\left.\left.\mathrm{IR}_{50}\right)^{\mathrm{n}_{\mathrm{H}}}\right)$ ], where $A_{1}$ is the maximum response plateau, $A_{2}$ is the minimum response plateau, IR is irradiance, $\mathrm{IR}_{50}$ represents the irradiance values that generate half-maximal response, and $n_{H}$ is the Hill slope. Light stimuli for all experiments were full-field, broadband white light of $83 \times 10^{4} \mu \mathrm{W} \cdot \mathrm{cm}^{-2}\left(5.87 \times 10^{16}, 5.03 \times 10^{16}, 6.18 \times 10^{14}\right.$ photons $\cdot \mathrm{cm}^{-2} \cdot \mathrm{s}^{-1}$ measured at 480,500 , and $360 \mathrm{~nm}$ respectively by interposing a narrow bandpass filter) delivered using a xenon lamp feeding the camera port. The field of the stimulus was sufficiently large to encompass the entire ipRGC arbors, and the focal plane of the stimulus was in the ganglion cell layer. A filter wheel fitted with various narrow bandpass (10 $\mathrm{nm}$ bandwidth) and neutral-density filters (Chroma Technologies) and shutter (Lambda-3, Sutter Instruments) was used to control the intensity and duration of light stimuli. White light was used in most experiments so as to not preferentially activate either the melanopsin, M-cone, or rod photopigments, and so light intensities are reported in terms of the log relative intensity $\left(\log _{I}\right)$ for white-light experiments. For single intensity experiments, stimuli were delivered at $-2 \log _{I}$. Irradiance measurements were made with a calibrated radiometer model S370 (UDT Instruments). In spectral experiments, cells were stimuluated with full-field light at $360 \mathrm{~nm}$ or 500 light. Neutral density filters were interposed in the light path resulting in stimulation intensities of -4.5 , $-3.0,-2,5,-2.0,-1.5,-1.0,-0.5$, and $-0 \log _{I}$ for $360 \mathrm{~nm}$ and -7.5 to $-0 \log _{I}$ (increasing in intensity by $0.5 \log _{I} /$ stimulation) for $500 \mathrm{~nm}$ stimuli. Threshold was defined as the intensity at which a light-evoked depolarization was first visible. The first stimulus of each wavelength was subthreshold and elicited no response in any cells tested. Though gradients of expression in $\mathrm{M}$ and $\mathrm{S}$ pigments have been demonstrated across the retina (Applebury et al., 2000), we did not preferentially sample cells based on region.

For experiments where $V_{\mathrm{m}}$ was measured before and after L-AP4 application, cells were allowed 5-10 min of dark adaptation until a stable membrane potential was attained. After recording several minutes of baseline, recording continued as L-AP4 was applied and the cell was again allowed to attain a stable $V_{\mathrm{m}}$. L-AP4 was then washed off and the cell $V_{\mathrm{m}}$ allowed to stabilize. Current was never injected in experiments where $V_{\mathrm{m}}$ was the variable being measured, and in this case cells where the $V_{\mathrm{m}}$ did not reach $-40 \mathrm{mV}$ were discarded.

Loose patch recordings were performed by obtaining a 100-700 $\mathrm{M} \Omega$ seal and recording in voltage-clamp mode with a holding potential of 0 $\mathrm{mV}$. Cell-attached recordings were performed by obtaining a $\geq 1 \mathrm{G} \Omega$ seal and recording in voltage-clamp mode with a holding current equal to that of the membrane potential (Perkins, 2006). Pipette solution consisted of (in mM) $150 \mathrm{NaCl}, 10$ HEPES.

Statistical analyses were performed using Origin 7.5 (MicroCal). Statistical comparison of means was performed using a Student's $t$ test or one-way ANOVA with Tukey's post hoc test and significance was concluded when $p<0.05$. Data are presented as mean \pm SE.

Pharmacology. L-2-Amino-4-phosphonobutyrate (L-AP4), $100 \mu \mathrm{M}$, a group III metabotropic glutamate receptor (mGluR) agonist (Tocris Bioscience) that blocks photoreceptor to On bipolar cell signaling (Slaughter and Miller, 1981), was sometimes included in the bath solution and used to silence On-pathway inputs.

In some experiments, we used ionic Ames' media (Do et al., 2009), in which all calcium is replaced with cobalt to block synaptic transmission (in mM): $120 \mathrm{NaCl}, 23 \mathrm{NaHCO}_{3}, 3.1 \mathrm{KCl}, 0.5 \mathrm{KH}_{2} \mathrm{PO}_{4}, 2$ $\mathrm{CoCl}_{2}, 1.2 \mathrm{MgSO}_{4}, 6$ glucose. Ionic Ames' also differs from commercially available Ames' in that it is lacking the array of amino acids including L-glutamine. DL-2-Amino-4-phosphonobutyrate (DL-AP4), $250 \mu \mathrm{M}$ (a group III metabotropic glutamate receptor (mGluR) agonist) (Tocris Bioscience), was then bath applied to ensure no effect of this drug on resting membrane potential.

Immunocytochemistry. Immunocytochemistry, neurobiotin filling and image analysis of retinas were performed as published previously (Schmidt et al., 2008). Cells were filled with $0.3 \%$ neurobiotin (Vector 
Labs) and visualized using Alexa Fluor-594conjugated streptavidin (Invitrogen). Goat anti-choline acetyltransferase (ChAT) was used to stain cholinergic amacrine cells (Millipore) and visualized with Alexa-488-conjugated donkey anti-goat secondary antibody (Invitrogen). Colocalization of EGFP and Melanopsin immunostaining was performed using a custommade antibody raised in rabbit to the $\mathrm{N}$ terminus region of the mouse melanopsin protein and goat anti-GFP conjugated to FITC primary antibodies, as well as Alexa-594conjugated anti-rabbit secondary antibody. Image acquisition was performed on an upright Olympus Fluoview 1000 laser scanning confocal microscope (Olympus) ImageJ was used to adjust image brightness and contrast (http://rsb.info.nih.gov/ij/) and neurons were traced and analyzed using NeuroLucida (MicroBrightField).

\section{Results}

M1 and M2 cells retain similar morphology and intrinsic membrane properties in Opn4 ${ }^{-/-}$mice

The purpose of this study was to examine the functional consequences of outer retinal signaling on ipRGCs. Because ipRGCs integrate synaptic input with their intrinsic, melanopsin-mediated photoresponse, it is difficult to measure synaptic inputs to ipRGCs in isolation. To circumvent this problem, we examined the light-evoked responses of ipRGCs in a mouse line which lacked expression of melanopsin $\left(O p n 4^{-/-}\right.$mouse line where the melanopsin gene is replaced by a taulacZ coding sequence, generously provided by Dr. King-Wai Yau, Johns Hopkins University, Baltimore, MD) (Hattar et al., 2002). To identify and target these cells for single cell electrophysiological recordings, we crossed the Opn $4^{-1-}$ mouse line with the previously characterized mouse line in which ipRGCs are labeled in vivo with enhanced green fluorescent protein (EGFP) (Schmidt et al., 2008). This strategy allowed us to identify and record from ipRGCs lacking the melanopsin protein and thus any intrinsic photosensitivity (Hattar et al., 2002). As expected, we observed excellent colocalization of EGFP and melanopsin in EGFP-Opn4 ${ }^{+/-}$mice, with $242 / 250$ (97\%) of melanopsin-positive cells costaining for EGFP, indicating the EGFP continues to reliably label ipRGCs in the Opn4 $4^{-\prime}$ - mouse line (data not shown).

We first wanted to confirm that both M1 cells, with dendrites that stratify in the Off sublamina, and M2 cells, with dendrites that stratify in the On sublamina, are present in the Opn $4^{-1-}$ mouse because it has been reported that tau-lacZ labels only the dendrites of M1 cells (Hattar et al., 2002, 2006; Baver et al., 2008) in Opn $4^{-/-}$mice. To test this, we recorded from EGFPpositive cells in Opn $4^{-/-}$mice with neurobiotin-filled pipettes. We then processed these retinas for expression of ChAT, a marker of cholinergic amacrine cells whose cell bodies are found in both the ganglion cell layer and inner nuclear layer (INL), and visualized neurobiotin-filled cells with Alexa Fluor-594conjugated streptavidin. The plexuses of cholinergic amacrine cells served as a visual marker for the Off and On sublaminas of the IPL. Neurobiotin-filled EGFP-positive cells revealed both
M1

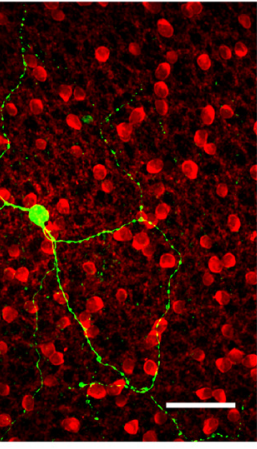

M2

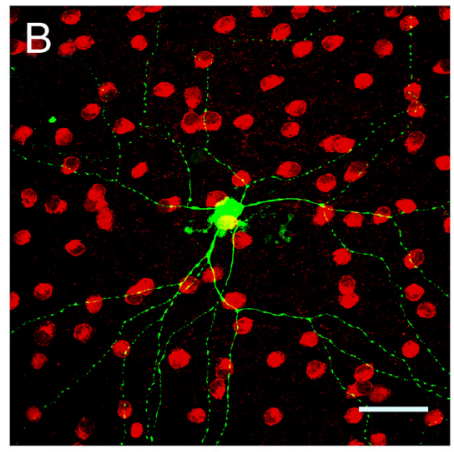

Figure 1. ipRGC morphology in Opn $4^{-1-}$ mice. $A, B$, Confocal stacks of whole-mount retinas in which an $M 1$ and $M 2$ cell have filled with neurobiotin (green) and costained for ChAT (red), a cholinergic amacrine cell marker. $A, M 1$ cell with dendrites the patching procedure. $\boldsymbol{C}, \boldsymbol{D}$, Sholl analysis (15 $\mu \mathrm{m}$ steps from starting diameter of $10 \mu \mathrm{m})$ of $\mathrm{M} 1(\boldsymbol{C})$ and $\mathrm{M} 2$ (D) dendritic arbors - (open circles) mouse lines. GCL, Ganglion cell layer. Scale bars: $\boldsymbol{A}, \boldsymbol{B}, 50 \mu \mathrm{m}$.

Off- and On-stratifying cells in the Opn $4^{-/-}$mouse, consistent with the presence of M1 and M2 subtypes in mice lacking expression of the melanopsin protein (Fig. $1 A, B$ ).

Before examining the role of synaptic inputs in mediating the light-evoked responses of ipRGCs in the Opn $4^{-1-}$ mice, we needed first to examine whether ipRGCs develop normally in these mice. We performed a quantitative examination of the morphological features of ipRGCs in Opn $4^{-/-}$mice at adult stages and compared them with those obtained in wild-type (WT) mice to test for morphological abnormalities (Fig. 1). Individual cells filled with neurobiotin were imaged and tracings were created to obtain an estimation of M1 and M2 cell soma size and dendritic field properties. M1 cells in the WT and Opn $4^{-\prime-}$ mice were similar in terms of their dendritic field diameter (WT: $391.2 \pm 24.5 \mu \mathrm{m}, n=12$; Opn $4^{-/-}: 421.1 \pm 35.8 \mu \mathrm{m}, n=9, p>$ $0.05, t$ test), total dendritic length (WT: $2846.1 \pm 379.0 \mu \mathrm{m}, n=$ 12; Opn4 $4^{-/-}: 2740.1 \pm 278.2 \mu \mathrm{m}, n=9, p>0.05, t$ test), and soma diameter (WT: $16.9 \pm 0.7 \mu \mathrm{m}, n=12 ; O p n 4^{-1-}: 16.8 \pm 0.6$ $\mu \mathrm{m}, n=9, p>0.05$, $t$ test). M2 cells were also similar in WT and $O p n 4^{-/-}$mice in their dendritic field diameter (WT: $445.4 \pm$ $18.8 \mu \mathrm{m}, n=7$; Opn $4^{-/-}: 486.5 \pm 22.1 \mu \mathrm{m}, n=11, p>0.05, t$ test), total dendritic length (WT: $4919.8 \pm 273.5 \mu \mathrm{m}, n=7$; Opn $4^{-1-}: 5244.8 \pm 314.4 \mu \mathrm{m}, n=11, p>0.05, t$ test $)$, and soma diameter (WT: $20.0 \pm 0.6 \mu \mathrm{m}, n=7$; Opn $4^{-/-}: 20.8 \pm 0.6 \mu \mathrm{m}$, $n=11, p>0.05, t$ test). Furthermore, when we analyzed the dendritic arbor complexity of ipRGCs using Sholl analysis, we found that M1 and M2 cells were similar between WT and 
Opn $4^{-1-}$ (Fig. 1C,D), demonstrating that ipRGCs develop normal morphology in the absence of the melanopsin protein.

To examine possible functional changes in Opn $4^{-/-}$ipRGCs, we determined ipRGC intrinsic membrane properties and compared them with those in WT mice. We found that $C_{\mathrm{m}}$ and $R_{\mathrm{N}}$ of M1 cells in WT $\left(C_{\mathrm{m}}=26.7 \pm 2.2 \mathrm{pF}, n=12 ; R_{\mathrm{N}}=1027.6 \pm\right.$ 111.3 M $\Omega, n=12$ ) were not significantly different from M1 cells in the Opn $4^{-1-}$ mouse $\left(C_{\mathrm{m}}=25.0 \pm 2.2 \mathrm{pF}, n=8, p>0.05, t\right.$ test; $R_{\mathrm{N}}=1302.9 \pm 173.0 \mathrm{M} \Omega, n=8, p>0.05, t$ test). Similarly, in $\mathrm{M} 2$ cells, $C_{\mathrm{m}}$ and $R_{\mathrm{N}}$ were not significantly different between $\mathrm{WT}\left(C_{\mathrm{m}}=37.8 \pm 2.5 \mathrm{pF}, n=15 ; R_{\mathrm{N}}=297.3 \pm 18.3 \mathrm{M} \Omega, n=15\right)$ and $O p n 4^{-1-}\left(C_{\mathrm{m}}=31.1 \pm 2.7 \mathrm{pF}, n=7, p>0.05, t\right.$ test; $R_{\mathrm{N}}=$ $266.9 \pm 25.7 \mathrm{M} \Omega, n=7, p>0.05, t$ test). Consequently, lack of melanopsin expression in ipRGCs and therefore intrinsic photosensitivity did not affect the overall development of these cells, at least in regard to their structure and intrinsic membrane properties.

\section{The On pathway is the primary synaptic input to both M1 and M2 cells}

Because M1 and M2 ipRGCs show apparently normal development in Opn $4^{-/-}$animals, we proceeded to examine the lightevoked synaptic currents in Opn $4^{-/-}$ipRGCs. We performed whole-cell voltage-clamp recordings in intact retinas from Opn $4^{-/-}$mice. M1 and M2 cells were held at $-73 \mathrm{mV}$ and then light-evoked responses were recorded to a $10 \mathrm{~s}$, bright, full-field, white light stimulus. Alexa Fluor-594 dye was included in the pipette solution for these and all subsequent recordings so that following recordings, ipRGC subtypes could be identified using epifluorescence at $594 \mathrm{~nm}$ (Schmidt and Kofuji, 2009). Figure 2 shows examples of this experiment. Both M1 and M2 cells responded to light stimulation with an inward current at light onset (Fig. 2A,B). Light-evoked currents in both M1 and M2 cells were sustained during the $10 \mathrm{~s}$ light stimulus although the currents decreased in amplitude during this time period. To test whether the light responses were mediated by the On pathway, we subsequently added L-(+)-2-4-amino-4-phosphonobutyric acid (L-AP4) to the bath solution. L-AP4 is an agonist of the mGluR6 receptor and blocks the transmission of signals between rods/cones and On BCs (Slaughter and Miller, 1981). Light-evoked currents in both M1 cells and M2 cells were completely abolished upon L-AP4 application (Fig. 2A-C; M1: $n=5, \mathrm{M} 2: n=4$ ). The notable difference between the light-responses evoked in M1 and M2 cells was in their magnitude. Light-evoked currents amounted to only $-58 \pm 25.5 \mathrm{pA}$ in M1 cells $(n=10)$ while in M2 cells they amounted to $-200.3 \pm 33.3 \mathrm{pA}(n=8)$. These results indicate that the On pathway does indeed signal light increases to ipRGCs by eliciting fast synaptic currents, albeit of distinct magnitude, in $\mathrm{M} 1$ and M2 cells.

To examine the efficiency of synaptically mediated signaling to M1 and M2 cells, we performed whole-cell current-clamp recordings of light-evoked responses to 5 or $10 \mathrm{~s}$ light stimuli of ipRGCs in the Opn4 ${ }^{-/-}$mouse. We found that all M1 cells responded to the light stimulus, but with a relatively weak depolarization that was somewhat sustained throughout the light stimulus and did not persist following stimulus offset (Fig. $3 A$ ). M2 cells in the Opn $4^{-/-}$mouse, in contrast, responded to bright white-light with large, fast, and sustained depolarizations that terminated quickly following stimulus offset (Fig. 3B). M2 cells had a significantly larger light-evoked maximum depolarization to a $5 \mathrm{~s}$ bright white-light stimulus than did M1 cells (M1: $13.1 \pm$ $3.3 \mathrm{mV}, n=8$; M2: $25.3 \pm 2.4 \mathrm{mV}, n=7, p<0.05)$. In general we observed more robust light-evoked action potential dis-
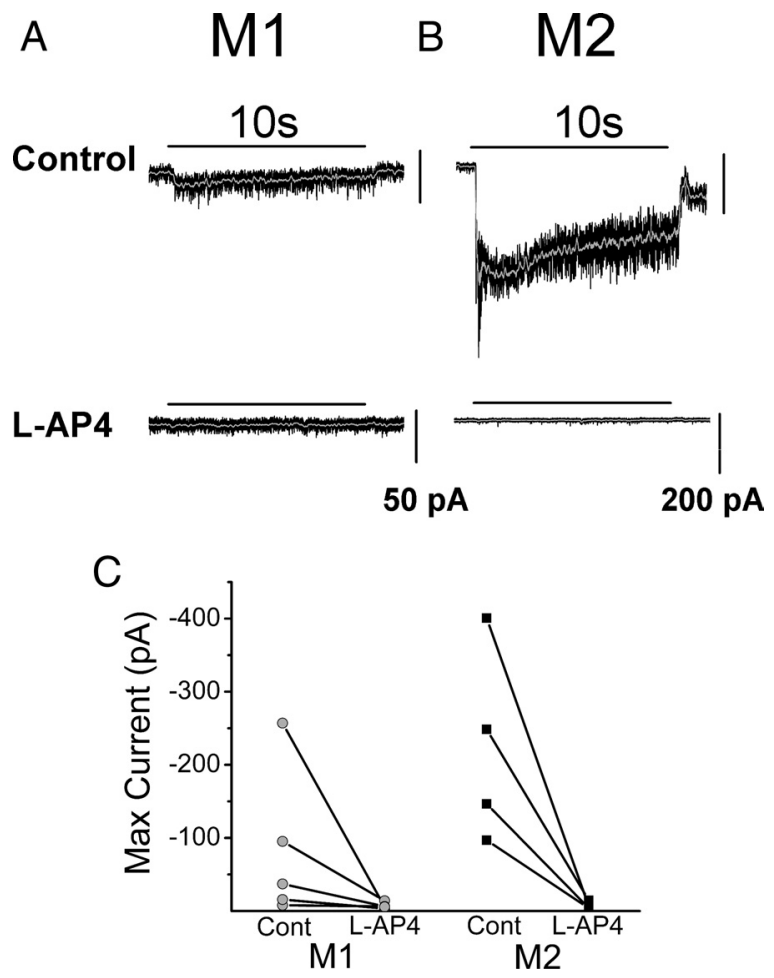

Figure 2. On pathway-evoked currents in $M 1$ and $M 2$ cells of $0 p n 4^{-1-}$ mice. Voltageclamp recordings ( $V_{\text {Hold }}=-73 \mathrm{mV}$ ) of light-evoked current in $\mathrm{M} 1$ and $\mathrm{M} 2$ ipRGCs of the Opn4 ${ }^{-/-}$mouse line to a $10 \mathrm{~s}$, full-field, bright white-light stimulus at $-2 \log _{\text {, }}$ before and after $100 \mu \mathrm{m}$ L-AP4 application. $\boldsymbol{A}, \boldsymbol{B}$, Light-evoked inward current of M1 $(\boldsymbol{A})$ and $\mathrm{M} 2(\boldsymbol{B})$ cell in control (top) and after 5 min of $100 \mu \mathrm{M} \mathrm{L-AP4}$ application (bottom) ( $n=5 \mathrm{M} 1 ; n=4 \mathrm{M} 2)$. $\boldsymbol{C}$ Maximum light-evoked current in M1 (gray) and M2 (black) cells before and after L-AP4 application. Light-evoked currents were completely abolished following blockade of the Onpathway input. Gray line indicates $0.1 \mathrm{~s} \mathrm{smoothing} \mathrm{of} \mathrm{membrane} \mathrm{current.}$

charge in M2 than M1 cells, consistent with previous reports that M2 cells attain higher firing frequencies than M1 cells (Schmidt and Kofuji, 2009). As expected, light responses were completely and reversibly abolished for both M1 $(n=3)$ and M2 cells $(n=3)$ in the presence of L-AP4 (Fig. 3A,B). These and the previous results indicate that the outer retinal input to ipRGCs is able to evoke light-mediated depolarization in both ipRGC subtypes, but that these responses are significantly larger in M2 than M1 cells. Differences in synaptic responses observed between M1 and M2 cells were not due to temperature because when preparations were acutely warmed to $34^{\circ} \mathrm{C}$, similar light response characteristics were observed for both M1 $(n=3)$ and M2 $(n=3)$ cells as seen at room temperature (data not shown).

To further examine the source of the synaptic input to M1 and M2 cells, irradiance response experiments using narrowbandpass-filtered 360 or $500 \mathrm{~nm}$ light were performed in Opn $4^{-1-}$ mice. At these wavelengths, light should effectively stimulate $S$-cone pigment $\left(\lambda_{\max }=360 \mathrm{~nm}\right)$ and M-cone pigment $\left(\lambda_{\max }=511 \mathrm{~nm}\right)$, with $360 \mathrm{~nm}$ light stimulating S-cone pigment $\sim 10$-fold more than $\mathrm{M}$-cone pigment and $500 \mathrm{~nm}$ light stimulating $\mathrm{M}$-cone pigment $>100,000$-fold more than S-cone pigment (Jacobs et al., 1991; Nikonov et al., 2006). All M1 cells stimulated with either $500 \mathrm{~nm}(n=7)$ or $360 \mathrm{~nm}(n=5)$ light responded with a sustained depolarization (Fig. 4A,C). The average stimulus intensity at which a response was first observed in M1 cells was $12.3 \pm 0.7 \log$ photons $\cdot \mathrm{cm}^{-2} \cdot \mathrm{s}^{-1}$ for $500 \mathrm{~nm}$ light and $12.1 \pm 0.3 \log$ photons $\cdot \mathrm{cm}^{-2} \cdot \mathrm{s}^{-1}$ for $360 \mathrm{~nm}$ light, within 


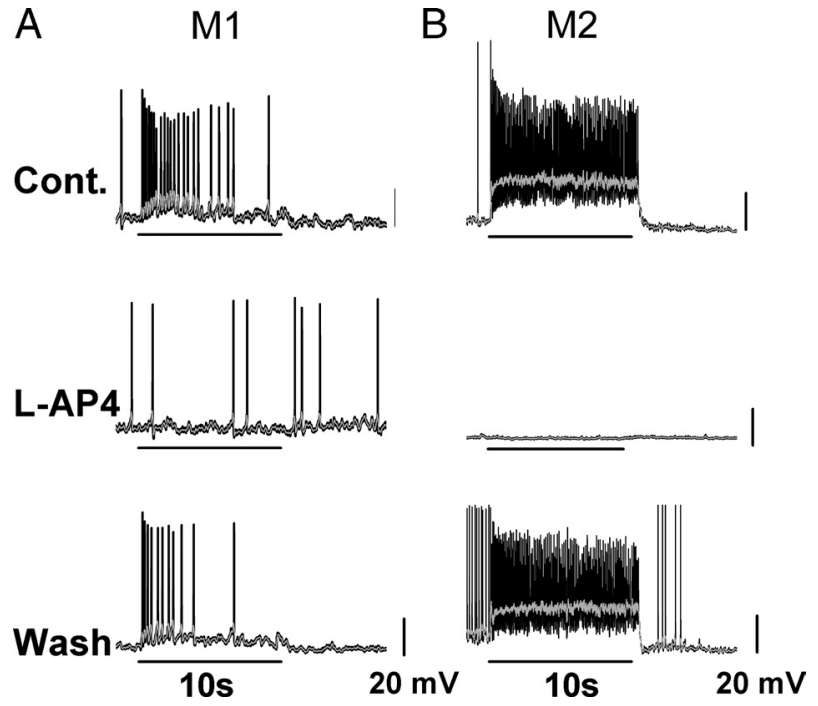

Figure 3. On pathway-evoked depolarization in $\mathrm{M} 1$ and $\mathrm{M} 2$ cells of $0 \mathrm{pn} 4^{-/-}$mice. Current-clamp recordings in $0 p n 4^{-1-}$ mouse line of $M 1$ and $M 2$ cell responses to a bright white light stimulus. $\boldsymbol{A}, \mathrm{M} 1$ cell response in current-clamp mode to $10 \mathrm{~s}$ bright, full-field, white-

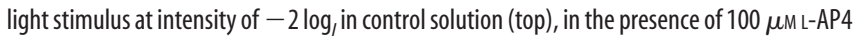
in the bath (middle), and after washout (bottom). Light responses of M1 cells in Opn4 ${ }^{-1-}$ mouse were completely abolished in the presence of L-AP4. B, M2 cell responses in currentclamp mode to $10 \mathrm{~s}$ bright, full-field, white light stimulus at intensity of $-2 \log$, in control solution (top), in the presence of $100 \mu \mathrm{m} \mathrm{L-AP4}$ in the bath (middle), and after washout (bottom). Light response of $\mathrm{M} 2$ cells in Opn $4^{-/-}$mouse were completely abolished in the presence of L-AP4. Gray lines indicate $0.1 \mathrm{~s} \mathrm{smoothing} \mathrm{of} \mathrm{membrane} \mathrm{voltage.}$

the photopic range (Dacey et al., 2005) (Fig. 4E). Furthermore, all M2 cells stimulated with either $500 \mathrm{~nm}(n=7)$ or $360 \mathrm{~nm}$ $(n=5)$ light responded with large, fast, and sustained depolarizations (Fig. 4B,D). The average stimulus intensity at which a response was first observed in M2 cells was $11.6 \pm 0.4$ $\log$ photons $\cdot \mathrm{cm}^{-2} \cdot \mathrm{s}^{-1}$ for $500 \mathrm{~nm}$ and $11.9 \pm 0 \log$ photons $\cdot \mathrm{cm}^{-2} \cdot \mathrm{s}^{-1}$ for $360 \mathrm{~nm}$, within the photopic range (Fig. 4E) (Dacey et al., 2005). The fact that the threshold for M1 and $\mathrm{M} 2$ cell responses is within the photopic range indicates that the responses measured in this study are most likely originating from the cone On pathway. This is unsurprising given that we are recording ipRGC responses in the isolated retinal preparation where the retina is physically isolated from the retinal pigmented epithelium so that cones, but not rods, are able to regenerate chromophore and avoid bleaching (Wang et al., 2009; Wang and Kefalov, 2009). Furthermore, the fact that ipRGCs receive light-evoked synaptic inputs at both 360 and $500 \mathrm{~nm}$ with similar thresholds indicates that both $\mathrm{S}\left(\lambda_{\max }=360 \mathrm{~nm}\right)$ and $\mathrm{M}\left(\lambda_{\max }=511 \mathrm{~nm}\right)$ cone pigments might participate in ipRGC synaptic signaling.

\section{Integrated light-evoked current of M2, but not M1 cells, is dominated by On pathway}

Subsequent experiments were focused on comparing the magnitude of the contribution of intrinsic (i.e., melanopsin-mediated) and extrinsic (i.e., synaptically mediated) light-evoked responses in M1 and M2 cells. We first recorded in voltage-clamp mode from WT mice in which both the synaptic and melanopsinmediated light responses are present. In these animals, M1 cell light responses to $10 \mathrm{~s}$ bright white light stimuli in WT mice were dominated by large, slow, and sustained inward currents similar to those reported previously (Berson et al., 2002; Schmidt and Kofuji, 2009) (Max current: $-206.3 \pm 23.4 \mathrm{pA}, n=8$; total

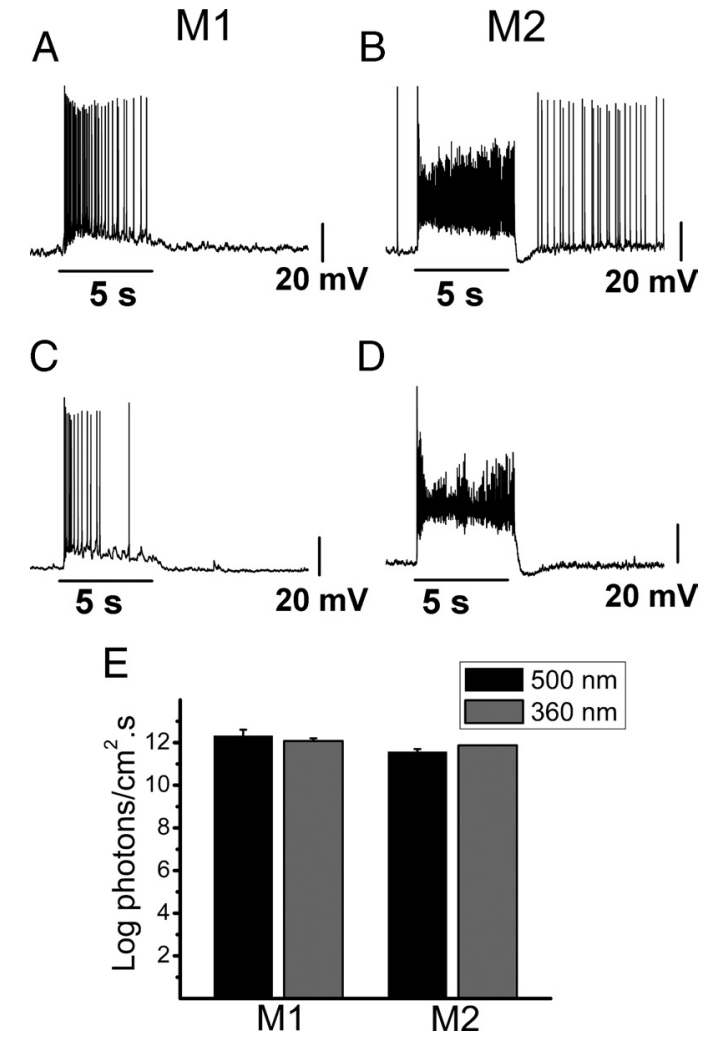

Figure 4. Synaptic responses of $M 1$ and $M 2$ cells in $0 p n 4^{-/-}$mice to 500 and $360 \mathrm{~nm}$ light. Current-clamp recordings of light-evoked depolarization of $\mathrm{M} 1$ and $\mathrm{M} 2$ cells to $5 \mathrm{~s} 500$ or $360 \mathrm{~nm}$ light stimulation of increasing intensities. $\boldsymbol{A}-\boldsymbol{D}$, Representative examples of light-evoked depolarization of M1 cell to $500 \mathrm{~nm}$ light stimulus at $15.2 \log$ photons $\cdot \mathrm{cm}^{-2} \cdot \mathrm{s}^{-1}(A), \mathrm{M} 2$ cell to $500 \mathrm{~nm}$ light stimulus at $14.7 \mathrm{log}$ photons $\cdot \mathrm{cm}^{-2} \cdot \mathrm{s}^{-1}(\boldsymbol{B}), \mathrm{M} 1$ cell to $360 \mathrm{~nm}$ light stimulus at $13.4 \log$ photons $\cdot \mathrm{cm}^{-2} \cdot \mathrm{s}^{-1}(\boldsymbol{C})$, and M2 cell to $360 \mathrm{~nm}$ light stimulus at $12.9 \log$ photons $\cdot \mathrm{cm}^{-2} \cdot \mathrm{s}^{-1}(\boldsymbol{D})$. $\boldsymbol{E}$, Average intensity $\left(\log\right.$ photons $\left.\cdot \mathrm{cm}^{-2} \cdot \mathrm{s}^{-1}\right)$ at which a synaptic response was detectable for $\mathrm{M} 1$ and $\mathrm{M} 2$ cells to $500 \mathrm{~nm}$ (black bars) and $360 \mathrm{~nm}$ (gray bars) light stimuli.

charge: $796.9 \pm 63.1 \mathrm{pC}, n=8$ ) (Fig. $5 A, C, D$ ). Light responses in WT M1 cells persisted for several seconds following the termination of light stimulus (DT: $3345.0 \pm 651.3 \mathrm{~ms}, n=8$ ). M2 cells in WT mice showed a large, fast inward current that quickly terminated following light offset (Max current: $-125.0 \pm 22.3 \mathrm{pA}, n=$ 6; total charge: $829.4 \pm 147.4 \mathrm{pC}, n=6$; DT: $506.1 \pm 72.0 \mathrm{~ms}, n=$ 6) (Fig. $5 A, C, D$ ). In contrast, in Opn $4^{-1-}$ mice in which the intrinsic photosensitivity is lacking, M1 cells responded to light with a significantly smaller inward current and significantly less charge throughout the light stimulus compared with WT (Max current: $-58.0 \pm 25.5 \mathrm{pA}, n=10, p<0.05, t$ test; total charge: $259.2 \pm 111.5$ pC, $n=10, p<0.05$, $t$ test) (Fig. $5 B, C, D$ ). M1 cell light responses terminated significantly faster in the knock-out mouse (DT $=324.1 \pm 69.4 \mathrm{~ms}, n=10, p<0.001, t$ test $)$ compared with WT. M2 cells in the Opn $4^{-1-}$ mice, in contrast, had light responses that were indistinguishable from WT (Max current: $-200.3 \pm 33.3 \mathrm{pA}, n=8, p>0.05, t$ test; total charge: $1333.7 \pm 279.3 \mathrm{pC}, n=8, p>0.05, t$ test; DT: $366.9 \pm 73.6 \mathrm{~ms}$, $n=8, p>0.05$, $t$ test) (Fig. $5 B, C, D$ ). Thus, light responses in M1 cells are driven primarily by their intrinsic photosensitivity and exhibit the long-latency and prolonged time course following light stimulation characteristic of melanopsin-mediated phototransduction. The dominant role of intrinsic photosensitivity for M1 cell photic responses is confirmed in the Opn $4^{-/-}$mice where the light-evoked responses were significantly smaller than 


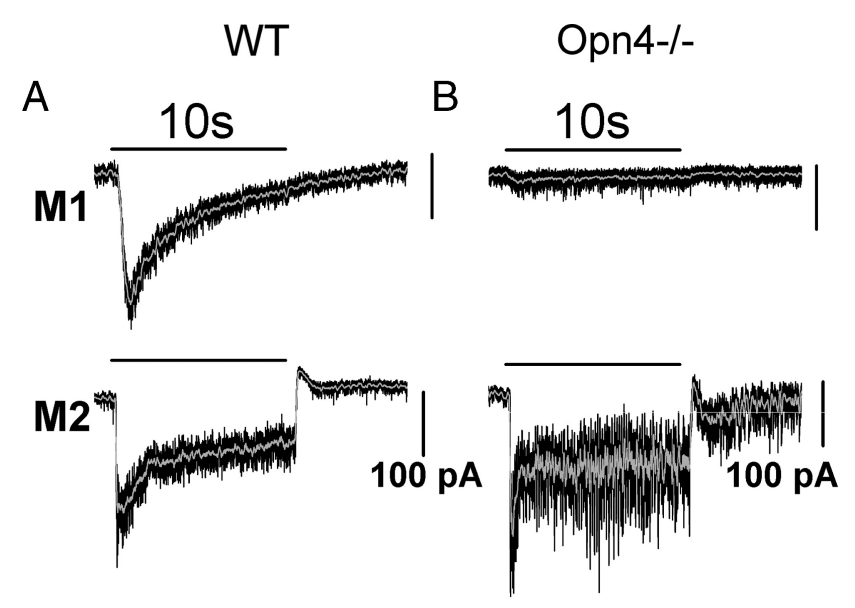

C

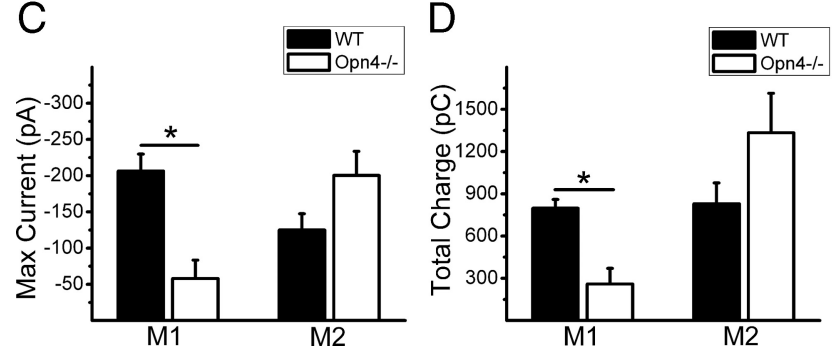

Figure 5. Light-evoked current in WT and Opn4 ${ }^{-/-}$ipRGCs. Voltage-clamp recordings $\left(V_{\text {Hold }}=-73 \mathrm{mV}\right)$ of light-evoked current to a $10 \mathrm{~s}$, full-field, bright, white-light stimulus at

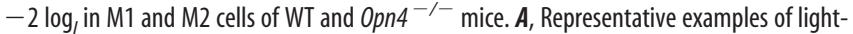
evoked inward current of M1 (top) and M2 (bottom) cells in a WT mouse. $\boldsymbol{B}$, Representative examples of light-evoked inward current of M1 (top) and M2 (bottom) cells in an Opn4 $4^{-/-}$ mouse. C, Mean \pm SE maximum current measured during the 10 s light stimulus in $\mathrm{M} 1$ ( $n=8$ WT; $n=100 \mathrm{pn} 4^{-/-}$) and M2 ( $n=6 \mathrm{WT} ; n=80 \mathrm{pn4^{-/- }}{ }^{-}$) cells of WT (black bars) and $O p n 4^{-1-}$ (white bars). Notice the reduced current in the $0 p n 4^{-1-}$ M1 but not M2 cells. $D$, Mean \pm SE total charge measured during 10 s light stimulus in M1 ( $n=8 \mathrm{WT} ; n=10$

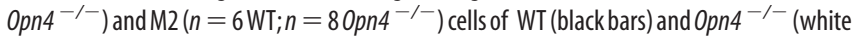
bars). Notice the reduced charge in the $0 p n 4^{-/-} M 1$ but not $M 2$ cells. Gray lines indicate $0.1 \mathrm{~s}$ smoothing of membrane voltage. ${ }^{*} p<0.05$, $t$ test.

in WT. Light responses in M2 cells, on the other hand, are driven primarily by the On pathway via synaptic transmission at photopic light intensities. Light responses exhibit comparatively faster kinetics of activation and termination than M1 cells, and responses of M2 cells were largely preserved in the melanopsinnull mice.

\section{On-pathway input strongly modulates light response of M2 ipRGCs}

Our results recorded in voltage clamp indicate that the integrated light-evoked current of M1 cells is dominated by the intrinsic photoreceptive system while the integrated light-evoked current of M2 cells is dominated by cone-mediated On-pathway input at bright light intensities. Given the diversity of the intrinsic membrane properties (Schmidt and Kofuji, 2009), and degree of intrinsic and extrinsic influences on M1 versus M2 cells, we hypothesized that the On channel inputs might differentially modulate the light response of these two distinct ipRGC subtypes. To test this, we recorded light responses in whole-cell current-clamp mode from WT M1 and M2 ipRGCs to a $5 \mathrm{~s}$ bright, full-field, white light stimulus first in control Ames' media and then following inclusion of $100 \mu \mathrm{M} \mathrm{L}-\mathrm{AP} 4$ in bath to selectively silence On channel inputs. Both M1 and M2 cells responded to the light stimulation with large, rapid depolarizations (Fig. 6A,B). Upon bath application of L-AP4, M2 cells responded

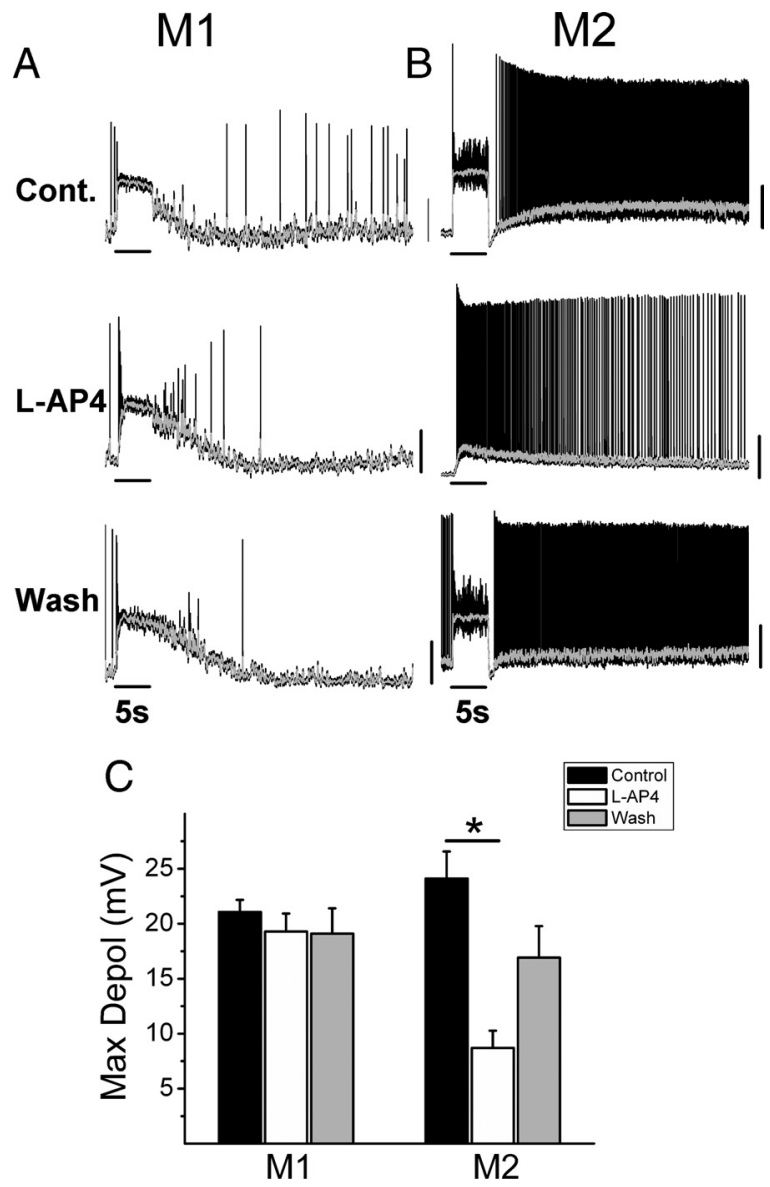

Figure 6. Contribution of On channel input to light response of M1 and M2 ipRGCs in WT mouse. $A, M 1$ cell response in current-clamp mode to $5 \mathrm{~s}$ bright, full-field, white-light stimulus

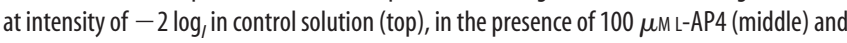
after washout (bottom). $\boldsymbol{B}, \mathrm{M} 2$ cell response in current-clamp mode to $5 \mathrm{~s}$ bright, full-field, white-light stimulus at intensity of $-2 \log$, in control solution (top), with $100 \mu \mathrm{M} \mathrm{L-AP4}$ in the bath (middle) and after washout (bottom). C, Mean \pm SE maximum depolarization for M1 ( $n=8$ cells) and M2 ( $n=9$ cells) in control solution (black bars), $100 \mu \mathrm{m} \mathrm{L-AP4} \mathrm{(white} \mathrm{bars),}$ and after washout (gray bars). Gray line in $A, B$ indicates $0.1 \mathrm{~s}$ smoothing of membrane voltage. ${ }^{*} p<0.05$, one-way ANOVA. Vertical scale bars $(\boldsymbol{A}, \boldsymbol{B}) 20 \mathrm{mV}$.

to light with small, sluggish depolarizations (Fig. 6B), consistent with the intrinsic, melanopsin-mediated response of M2 cells previously reported (Schmidt et al., 2008; Schmidt and Kofuji, 2009). M1 cells, however, continued to respond to bright light stimulation with large depolarizations, and only a small decrease in latency (Fig. 6A). These effects were reversed upon washout (Fig. 6A,B). When the maximum depolarization evoked by light was quantified, $M 2$ cells did indeed show a significant decrease in the maximum light-evoked depolarization in the presence of L-AP4 (control: $24.1 \pm 2.4 \mathrm{mV}$ vs L-AP4: $8.7 \pm 1.6 \mathrm{mV}, n=9, p<$ 0.05, One-way ANOVA) (Fig. 6C). L-AP4 application to M2 cells also resulted in a significant increase of $10-90 \%$ in RT $(2.1 \pm$ $0.7 \mathrm{~s}, n=9, p<0.05, t$ test) as well as a significant increase in DT to $37 \%$ of maximum $(20.8 \pm 5.4 \mathrm{~s}, n=7, p<0.01, t$ test $)$. The light-evoked depolarization of M1 cells in control vs L-AP4 conditions did not change (control: $21.1 \pm 1.1 \mathrm{mV}$ vs L-AP4: $19.3 \pm$ $1.6 \mathrm{mV}, n=8, p>0.05$, One-way ANOVA) (Figure 6C). Furthermore, there were no significant changes in RT $(0.18 \pm 0.2 \mathrm{~s}$, $n=8, p>0.05, t$ test $)$ and DT $(0.07 \pm 0.8 \mathrm{~s}, n=8, p>0.05, t$ test $)$ following L-AP4 application to M1 cells. These results indicate that the On-pathway makes a relatively minor contribution to the total light-evoked depolarization observed in M1 cells and does 
not significantly affect the latency at light onset or offset for the M1 population as a whole. In contrast, the On pathway evokes a sustained light-evoked depolarization in M2 cells that served to enhance both the magnitude and kinetics of the light response at photopic light intensities.

To ensure that the patterns observed were not attributable to washout of the intrinsic response due to dialysis of the intracellular contents as a result of the whole-cell recording mode, we also performed extracellular loose-patch or cell-attached recordings of M1 and M2 cells in the WT mouse. We found that under control conditions, M2 cells $(n=4)$ responded to increasing intensities of white light with short-latency responses of increasing spike frequency similar to those observed in whole-cell recordings (supplemental Fig. 1, available at www.jneurosci.org as supplemental material). M2 cells also showed cessation of firing at light offset followed by a rebound in the firing rate, consistent with patterns observed in whole-cell current-clamp mode (Fig. $6 B)$. Furthermore, application of L-AP4 to M2 cells $(n=5)$ resulted in a substantial reduction of both spike frequency and slower kinetics at light onset and offset (supplemental Fig. 1, available at www.jneurosci.org as supplemental material), with cells continuing to fire following light offset in the presence of L-AP4. These patterns again support our observations made in whole-cell recordings (Fig. $6 \mathrm{~B}$ ). Loose-patch or cell-attached recordings of M1 cells $(n=5)$ to increasing intensities of white light revealed responses that were relatively sluggish at lower light intensities and sustained at light offset, again similar to our wholecell recordings and consistent with the firing being driven primarily by melanopsin-mediated phototransduction (supplemental Fig. 2, available at www.jneurosci.org as supplemental material). Furthermore, upon L-AP4 application, no substantial differences were observed in the kinetics of the light response of M1 cells at light onset or offset $(n=3)$, again similar to the sustained depolarization at light offset observed our whole-cell recordings (supplemental Fig. 2, available at www.jneurosci.org as supplemental material; Fig. 6A). Collectively, our extracellular recording results support the results obtained in our whole-cell recordings that the primary influence on the light response of M2 cells is driven by the On pathway while M1 cells rely primarily on their intrinsic, melanopsin-mediated phototransduction.

We next investigated the effects of cone-driven On-pathway input on the intensity-response relations of M1 and M2 cells. Because M1 cells have been shown to be $\sim 1 \log$ unit more intrinsically sensitive to $480 \mathrm{~nm}$ light than M2 cells (Schmidt and Kofuji, 2009), we expected that the On channel input would differentially influence the overall light sensitivity of these two subtypes. To test this, we recorded responses in whole-cell current-clamp mode to increasing intensities of white light in the absence or presence of L-AP4. Both M1 and M2 cells responded to increasing intensities of light with increasing depolarization under both conditions. We observed small, fast synaptic inputs to M1 cells at low light intensities (Fig. 7A) that were not observed in the presence of L-AP4 (Fig. 7B). These synaptic responses were often first observed at intensities at or just subthreshold to the intrinsic response, which could clearly be discerned as a separate component at low light intensities in some M1 cells. When the normalized, maximum depolarization of M1 cells was averaged for each light intensity, we measured a significant increase in the maximum depolarization in control vs L-AP4 only at higher light intensities $\left(-4.5\right.$ and $-4 \log _{I}$, control: $n=8, \mathrm{~L}-\mathrm{AP} 4 n=5, p<$ $0.05, t$ test) but not near threshold. These results indicate that the On channel did not significantly influence the sensitivity of M1 cells either near threshold or near the IR50 (Fig. 7A-C), and may
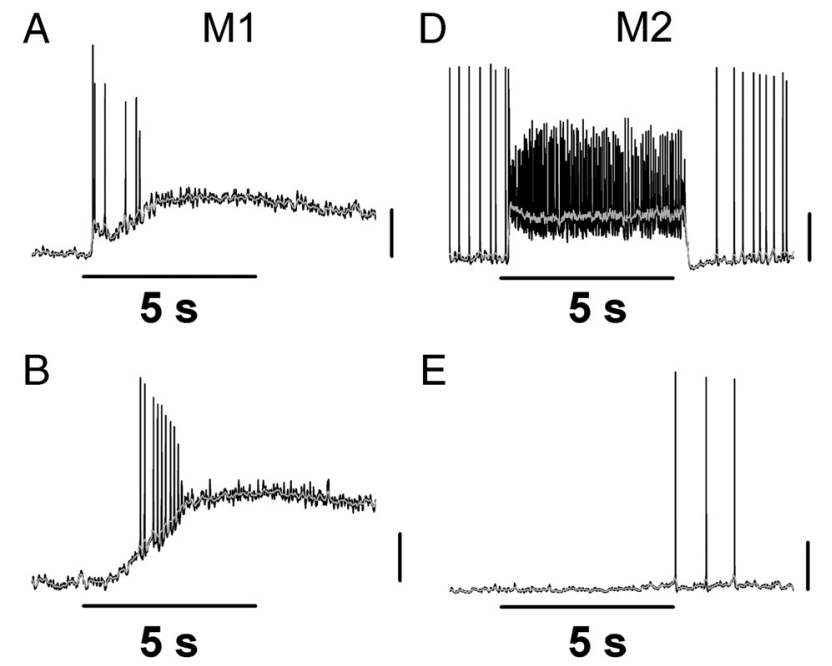

$\mathrm{C}$

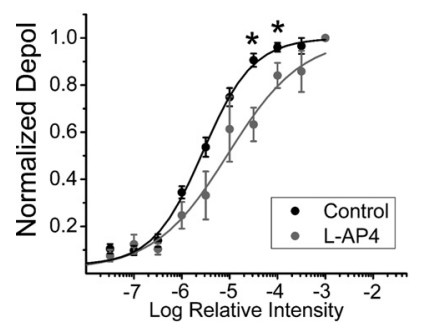

F

Figure 7. Effects of light-evoked $0 n$-pathway input on light sensitivity of $M 1$ and $M 2$ cells. $A$, $\boldsymbol{B}$, Representative responses of two $M 1$ cells to $5 \mathrm{~s}$, full-field, white light stimulus at $-5 \log$, in the absence $(\boldsymbol{A})$ or presence $(\boldsymbol{B})$ of $100 \mu \mathrm{m} \mathrm{L}-A P 4$. $\boldsymbol{C}$, Normalized, averaged responses of M1 cells in the absence (black, $n=8$ ) and presence (gray, $n=5$ ) of $100 \mu \mathrm{m} \mathrm{L-AP4}$ to increasing intensities of white light fit with logistic dose-response functions (see Materials and Methods). $D, E$, Representative responses of two M2 cells to $5 \mathrm{~s}$, full-field, white light stimulus at $-5 \mathrm{log}_{l}$ in the absence $(\boldsymbol{D})$ or presence $(\boldsymbol{E})$ of $100 \mu \mathrm{ML}-\mathrm{AP} 4 . \boldsymbol{F}$, Normalized and averaged responses of $\mathrm{M} 2$ cells in the absence (black, $n=8$ ) and presence (gray, $n=6$ ) of $100 \mu \mathrm{m} \mathrm{L-AP4} \mathrm{to} \mathrm{increasing}$ intensities of white light, fit with logistic dose-response functions (see Materials and Methods). Gray lines indicate $0.1 \mathrm{~s}$ smoothing of membrane voltage. $p<0.05, t$ test. Vertical scale bars: $(A-E), 20 \mathrm{mV}$.

actually serve to saturate the light response at lower light intensities. We also observed robust synaptic inputs to M2 cells at low light intensities in control conditions. The threshold for synaptically evoked responses occurred at intensities that were at least a log unit lower than the threshold for M2 cells observed in the presence of L-AP4 (Fig. 7D,E). When the normalized maximum depolarization of M2 cells was averaged for at each light intensity, we measured a significant increase in the normalized maximum depolarization in control vs L-AP4 at intensities near threshold $\left(-6,-5.5,-5 \log _{I}\right.$, control: $n=8$, L-AP4 $n=6, p<0.05, t$ test $)$, but not at higher light intensities. In the case of $\mathrm{M} 2$ cells, the On pathway greatly enhanced the response of M2 cells near threshold and served to increase the dynamic range of the response (Fig. $7 F$ ). These experiments again demonstrate that the cone-driven On-pathway has fundamentally distinct roles in shaping the light-evoked responses and sensitivity of M1 and M2 cells.

\section{ipRGCs are modulated by the On pathway in the dark}

In addition to mediating light-evoked signaling, previous research has demonstrated that the $V_{\mathrm{m}}$ of On and Off RGCs is modulated by the On pathway at rest (Zaghloul et al., 2003; Margolis and Detwiler, 2007). Because M1 and M2 ipRGCs have dendrites that stratify in the Off and On sublamina of the IPL, 
A

Cont.
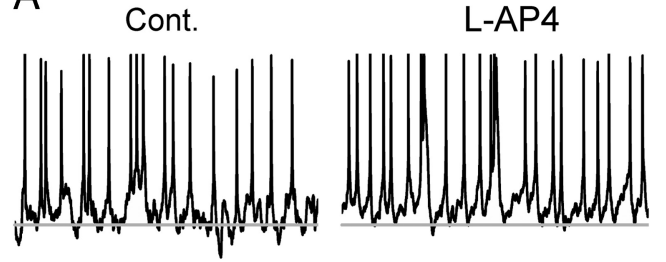

B
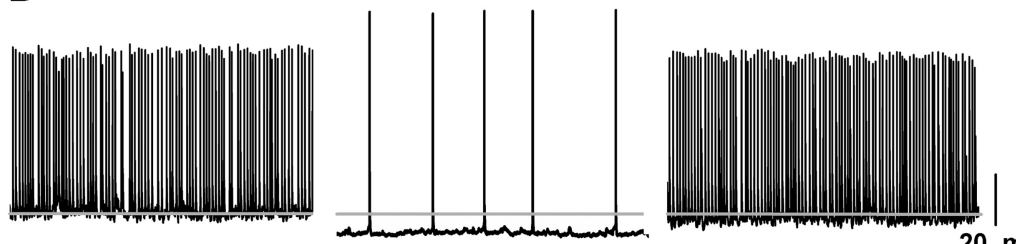

C
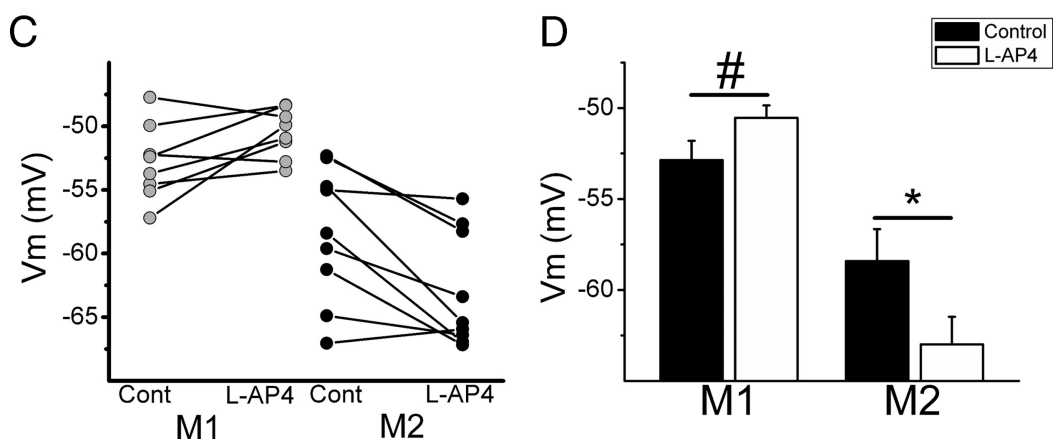

Figure 8. Modulation of ipRGC $V_{m}$ (in $\mathrm{mV}$ ) by the 0 n pathway. $\boldsymbol{A}, \boldsymbol{B}$, Whole-cell current-clamp recording of $\mathrm{M} 1(\boldsymbol{A})$ and $\mathrm{M} 2(\boldsymbol{B})$ cells where $V_{m}$ was recorded continuously (each panel indicates $10 \mathrm{~s}$ of recording) in the absence (left) and presence (middle) of $100 \mu \mathrm{m}$ L-AP4. Right panels show washout. $C, V_{\mathrm{m}}$ of individual M1 (gray, $n=8$ cells) and M2 (black, $n=9$ cells) cells in control solution and in the presence of $100 \mu \mathrm{M} \mathrm{L}-A$ P4. D, Mean \pm SE $V_{\mathrm{m}}$ of M1 ( $n=8$ cells) and M2 ( $n=9$ cells) in control solution (black bars) and in the presence of $100 \mu \mathrm{m} \mathrm{L-AP4}$ (white bars). Gray line indicates $-58 \mathrm{mV}$. ${ }^{*} p<0.05, t$ test, \#p<0.06,t test.

respectively, we hypothesized that the On pathway might also differentially modulate the resting discharge of M1 and M2 ipRGCs at rest. To test this hypothesis, we targeted single ipRGCs for whole-cell, current-clamp recordings in WT mice. After whole-cell access, we allowed cells to dark adapt for 5-10 min and then continuously monitored $V_{\mathrm{m}}$ in the absence and then presence of $100 \mu \mathrm{M} \mathrm{L}-\mathrm{AP} 4$ (Fig. $8 A, B$ ). Compared with control conditions $\left(V_{\mathrm{m}}=-58.4 \pm 1.8 \mathrm{mV}\right)$, M2 cells were significantly more hyperpolarized in the presence of L-AP4 $\left(V_{\mathrm{m}}=-63.0 \pm 1.5 \mathrm{mV}\right.$, $n=9, t$ test, $p<0.01$; Figure $8 B-D$ ), consistent with patterns observed by previous studies of other On RGC types (Margolis and Detwiler, 2007). M1 cells, in contrast, depolarized slightly upon L-AP4 application $(-50.5 \pm 0.7 \mathrm{mV})$ when compared with control conditions $(-52.9 \pm 1.1)$ though this trend was not significant $(n=8, p=0.053$, $t$ test; Figure $8 A, C, D)$. DL-AP4 application in ionic Ames' solution containing $2 \mathrm{~mm}$ cobalt (Do et al., 2009) (see Materials and Methods) to block all other synaptic transmission did not result in any changes in $V_{\mathrm{m}}$ of either M1 $(n=3)$ or M2 cells $(n=4)$ (data not shown), indicating that the effect of L-AP4 was not due to direct action on the ipRGCs themselves. Collectively these results indicate that the On pathway exerts a tonic excitatory influence on M2 cells at rest, but not on M1 cells.

\section{Note: “Atypical” M1 cells}

Very infrequently ( $n=4 / 36 \mathrm{M} 1$ cells), we encountered M1 cells with physiological characteristics that mimicked those of M2 cells. "Atypical" M1 cells hyperpolarized in response to L-AP4
$20 \mathrm{mV}$

application in the dark (supplemental Fig. $3 A$, available at www.jneurosci.org as supplemental material) and showed fast onset and offset kinetics when stimulated with light with little or none of the afterdischarge following light offset typical of M1 cells (supplemental Fig. 3B-D). These cells were qualitatively identifiable as outliers, and thus not included in the analyses though each cell had dendrites that clearly all stratified in the Off sublamina of the IPL. (Examples of each "atypical" M1 cell can be seen in supplemental Fig. 3, available at www.jneurosci.org as supplemental material.) "Atypical" M1 cells have relatively dim EGFP signals and large dendritic arbors that extend through the On sublamina before diving down into the Off sublamina of the IPL (Schmidt TM and Kofuji P, unpublished observations). These cells are very rare, and may be a developmental anomaly or an actual physiological subset of the M1 population.

\section{Discussion}

We have used pharmacological manipulations in a transgenic mouse line in which ipRGCs are labeled in vivo with EGFP in a wild-type or melanopsin-null genetic background to examine the relative influence of the On pathway on the lightevoked and resting discharge of M1 and M2 cells. The primary finding of this study is that the On pathway constitutes the dominant excitatory synaptic input to both M1 and M2 cells at bright light intensities. While this pathway is critical in shaping the light-evoked and resting discharge of M2 cells, the M1 cells are only modestly affected. Instead, M1 cells rely primarily on melanopsinmediated phototransduction to convey photic information to non-image-forming visual centers.

M1 cells morphologically resemble the Off RGCs in that the dendrites of M1 cells narrowly stratify in the outermost layer of the Off sublamina of the IPL while the dendrites of M2 cells stratify narrowly in the innermost layer of the IPL, morphologically paralleling On RGCs (Viney et al., 2007; Schmidt et al., 2008; Schmidt and Kofuji, 2009). It has been suggested that because M2 cells have such small, insensitive melanopsin-mediated photocurrent and low input resistance that synaptic inputs might be more influential in shaping the light response this ipRGC subtype (Schmidt and Kofuji, 2009; Bailes and Lucas, 2010). M1 cells, in contrast, with their large, sensitive melanopsin-mediated photocurrent and high input resistance, might be less influenced by synaptic inputs. Our results support these hypotheses, extending findings from our previous work to encompass diversity of not only intrinsic, but also synaptically evoked influences on M1 and M2 cell light responses. Recordings from Opn $4^{-/-}$mice indicate that M2 cells receive a large, excitatory cone-driven On-pathway synaptic input with light-evoked currents that displayed relatively fast kinetics upon light onset and offset and relatively sustained amplitude during the stimulus. Light-evoked synaptic currents in M1 cells were qualitatively similar, but their overall magnitude was consistently smaller than those recorded in M2 
cells. These differences in the excitatory drive by the conemediated On pathway were also seen in current-clamp recordings, with larger depolarizations for M2 cells than M1 cells. Furthermore, when we measured the integrated light-evoked current and depolarizations in WT mice, we found that with melanopsin-mediated signaling intact, the On pathway's contribution to the M1 cell light response was minimal. However, the light responses of M2 cells were largely unchanged in mouse lines where melanopsin-mediated signaling was intact (WT) or nonfunctional $\left(O p n 4^{-1-}\right)$. Furthermore, application of L-AP4 reduced the amplitude and slowed the kinetics of the M2 cell light response, indicating that the On pathway is the dominant influence during light stimulation for M2 cells.

We have demonstrated that M2 cells are depolarized by the On pathway at rest, indicating that there is a tonic excitatory drive to M2 cells, even in the dark, that can be blocked by L-AP4 application. M1 cells, in contrast, are possibly hyperpolarized by the On pathway in the dark, but the effect of L-AP4 application in depolarizing M1 cells was not significant. These data are in line with results reported previously indicating that other types of On RGCs are modulated by the On pathway rest (Margolis and Detwiler, 2007). M2 cells have a very hyperpolarized $V_{\mathrm{m}}$ when synaptic inputs are blocked, as well as a low input resistance (Schmidt and Kofuji, 2009). It is thus possible that a tonicdepolarizing drive via the On pathway serves to keep M2 cells close to or at threshold for action potential firing. The lack of a tonic excitatory drive to M1 cells in the dark is suggestive that their input synapses have a relatively low rate of basal glutamate release in the dark or are perhaps occurring at such low densities that they are not able to influence $V_{\mathrm{m}}$, especially with the large inhibitory drive these cells receive at rest (Wong et al., 2007; Dumitrescu et al., 2009).

Electron microscopy and immunohistochemical studies have identified synaptic contacts to On and Off-stratifying ipRGCs (Belenky et al., 2003; Jusuf et al., 2007; Østergaard et al., 2007). Recent work in both rodent and rabbit has identified en passant or ectopic synapses of On cone bipolar cells onto M1 ipRGCs as well as dopaminergic amacrine cells in the Off sublamina of the IPL (Dumitrescu et al., 2009; Hoshi et al., 2009). The study by Dumitrescu et al. (2009) demonstrated functionality of the On inputs to the displaced M1 cells, the somas of which are displaced in the INL and the dendrites of which never pass through the On sublamina. Furthermore, in the macaque, both On and Offstratifying ipRGCs (possible corollaries of M1 and M2 cells) were reported to receive similar excitatory drive at light onset, but differential influence of the On pathway was not reported (Dacey et al., 2005). Our study provides the first evidence that excitatory synaptic sites are not equally effective in driving light-evoked responses in ipRGC subtypes. Our approach using melanopsinnull mice to measure purely synaptic currents and depolarization of both nondisplaced M1 and also M2 cells has allowed, for the first time, examination of the properties of the synaptic inputs throughout the duration of the light stimulus without contamination by melanopsin-mediated signaling. The synaptic currents and depolarizations evoked in both M1 and M2 cells are relatively sustained compared with other ganglion cell types (Wong et al., 2007). It has been suggested that perhaps On bipolar cell inputs within the Off sublamina are more sustained than conventional On bipolar cell synapses within the On sublamina (Dumitrescu et al., 2009). However, the responses of M1 and M2 cells appear qualitatively similar, indicating that perhaps these subtypes of ipRGC could share input from a single cone bipolar cell subtype, which could be Type 6, 7 or 8 (Viney et al., 2007; Dumitrescu et al., 2009), with M1 cells receiving inputs within the "accessory On sublamina" reported by Dumitrescu et al. (2009) and M2 cells receiving these inputs via more conventional synapses with cone On bipolar cells in the On sublamina. M1 synaptic responses measured in melanopsin-null mice in both current and voltage clamp were consistently smaller than those of M2 cells, which could be due to the relatively low density of synapses to M1 cells relative to M2 cells (Jusuf et al., 2007; Dumitrescu et al., 2009). Alternatively, the smaller responses of M1 cells could be due to smaller net excitation due to the presence of inhibitory inputs (Wong et al., 2007).

Stimulation of both M1 and M2 ipRGCs with narrowbandpass-filtered 500 or $360 \mathrm{~nm}$ light resulted in responses in both subtypes, indicating that both the $\mathrm{S}$ and $\mathrm{M}$ cone pigments might be involved in synaptic signaling to ipRGCs. Furthermore, because, in our preparation, the threshold for responses to both of these wavelengths occurred within the photopic range (Dacey et al., 2005), it can be concluded that we are principally measuring cone signaling to ipRGCs. This is also supported by the fact that most of the recordings were performed in response to bright white light after partial light adaptation of the isolated retinal preparation with epifluorescent illumination to localize EGFPpositive cells.

M1 and M2 cells have been demonstrated to differentially and specifically project to different NIF nuclei in the brain, with M1 cells forming the primary projection to the SCN but both M1 and M2 cells substantially innervating the OPN (Baver et al., 2008; Ecker et al., 2010). Recent studies have highlighted an important role for rod, but apparently not cone, phototransduction in circadian photoentrainment (Altimus et al., 2010; Lall et al., 2010). Thus, our findings that M1 cells are not highly influenced by the cone pathway together with the fact that M1 cells form the primary projection to the SCN indicate that perhaps M1 cells serve mainly to relay rod and melanopsin-mediated information to NIF visual centers, while M2 cells are the primary conduit for cone-mediated information. This would implicate M2 cells in behaviors highly influenced by cone inputs through ipRGCs, such as the PLR (Lall et al., 2010). One might predict a larger influence of rod-mediated input on M1 vs M2 cell light responses, and this will be an important area for future study.

In summary, we demonstrate the distinctive synaptic influence from the On pathway on M1 and M2 cells. Our results suggest that M1 cells carry primarily information related to melanopsinmediated signaling while M2 cells are the primary conduit for conemediated signaling to non-image-forming brain centers. These findings further support the idea that distinct ipRGC subtypes may signal distinct light information to the brain and have distinct influences on non-image-forming behaviors.

\section{References}

Altimus CM, Güler AD, Alam NM, Arman AC, Prusky GT, Sampath AP, Hattar S (2010) Rod photoreceptors drive circadian photoentrainment across a wide range of light intensities. Nat Neurosci 13:1107-1112.

Applebury ML, Antoch MP, Baxter LC, Chun LL, Falk JD, Farhangfar F, Kage K, Krzystolik MG, Lyass LA, Robbins JT (2000) The murine cone photoreceptor: a single cone type expresses both $\mathrm{S}$ and $\mathrm{M}$ opsins with retinal spatial patterning. Neuron 27:513-523.

Bailes HJ, Lucas RJ (2010) Melanopsin and inner retinal photoreception. Cell Mol Life Sci 67:99-111.

Baver SB, Pickard GE, Sollars PJ, Pickard GE (2008) Two types of melanopsin retinal ganglion cell differentially innervate the hypothalamic suprachiasmatic nucleus and the olivary pretectal nucleus. Eur J Neurosci 27:1763-1770.

Belenky MA, Smeraski CA, Provencio I, Sollars PJ, Pickard GE (2003) Mela- 
nopsin retinal ganglion cells receive bipolar and amacrine cell synapses. J Comp Neurol 460:380-393.

Berson DM, Dunn FA, Takao M (2002) Phototransduction by retinal ganglion cells that set the circadian clock. Science 295:1070-1073.

Dacey DM, Liao HW, Peterson BB, Robinson FR, Smith VC, Pokorny J, Yau KW, Gamlin PD (2005) Melanopsin-expressing ganglion cells in primate retina signal colour and irradiance and project to the LGN. Nature 433:749-754

Do MT, Kang SH, Xue T, Zhong H, Liao HW, Bergles DE, Yau KW (2009) Photon capture and signalling by melanopsin retinal ganglion cells. Nature 457:281-287.

Dumitrescu ON, Pucci FG, Wong KY, Berson DM (2009) Ectopic retinal ON bipolar cell synapses in the OFF inner plexiform layer: contacts with dopaminergic amacrine cells and melanopsin ganglion cells. J Comp Neurol 517:226-244.

Ecker JL, Dumitrescu ON, Wong KY, Alam NM, Chen SK, LeGates T, Renna JM, Prusky GT, Berson DM, Hattar S (2010) Melanopsin-expressing retinal ganglion-cell photoreceptors: cellular diversity and role in pattern vision. Neuron 67:49-60.

Gooley JJ, Lu J, Chou TC, Scammell TE, Saper CB (2001) Melanopsin in cells of origin of the retinohypothalamic tract. Nat Neurosci 4:1165.

Gooley JJ, Lu J, Fischer D, Saper CB (2003) A broad role for melanopsin in nonvisual photoreception. J Neurosci 23:7093-7106.

Göz D, Studholme K, Lappi DA, Rollag MD, Provencio I, Morin LP (2008) Targeted destruction of photosensitive retinal ganglion cells with a saporin conjugate alters the effects of light on mouse circadian rhythms. PLoS One 3:e3153.

Güler AD, Ecker JL, Lall GS, Haq S, Altimus CM, Liao HW, Barnard AR, Cahill H, Badea TC, Zhao H, Hankins MW, Berson DM, Lucas RJ, Yau KW, Hattar S (2008) Melanopsin cells are the principal conduits for rod-cone input to non-image-forming vision. Nature 453:102-105.

Hannibal J, Fahrenkrug J (2004) Target areas innervated by PACAPimmunoreactive retinal ganglion cells. Cell Tissue Res 316:99-113.

Hatori M, Le H, Vollmers C, Keding SR, Tanaka N, Buch T, Waisman A, Schmedt C, Jegla T, Panda S (2008) Inducible ablation of melanopsinexpressing retinal ganglion cells reveals their central role in non-image forming visual responses. PLoS One 3:e2451.

Hattar S, Liao HW, Takao M, Berson DM, Yau KW (2002) Melanopsincontaining retinal ganglion cells: architecture, projections, and intrinsic photosensitivity. Science 295:1065-1070.

Hattar S, Kumar M, Park A, Tong P, Tung J, Yau KW, Berson DM (2006) Central projections of melanopsin-expressing retinal ganglion cells in the mouse. J Comp Neurol 497:326-349.

Hoshi H, Liu WL, Massey SC, Mills SL (2009) ON inputs to the OFF layer: bipolar cells that break the stratification rules of the retina. J Neurosci 29:8875-8883.

Jacobs GH, Neitz J, Deegan JF 2nd (1991) Retinal receptors in rodents maximally sensitive to ultraviolet light. Nature 353:655-656.

Jusuf PR, Lee SC, Hannibal J, Grünert U (2007) Characterization and syn- aptic connectivity of melanopsin-containing ganglion cells in the primate retina. Eur J Neurosci 26:2906-2921.

Lall GS, Revell VL, Momiji H, Al Enezi J, Altimus CM, Güler AD, Aguilar C, Cameron MA, Allender S, Hankins MW, Lucas RJ (2010) Distinct contributions of rod, cone, and melanopsin photoreceptors to encoding irradiance. Neuron 66:417-428.

Margolis DJ, Detwiler PB (2007) Different mechanisms generate maintained activity in ON and OFF retinal ganglion cells. J Neurosci 27: $5994-6005$.

Nikonov SS, Kholodenko R, Lem J, Pugh EN Jr (2006) Physiological features of the S- and M-cone photoreceptors of wild-type mice from singlecell recordings. J Gen Physiol 127:359-374.

Østergaard J, Hannibal J, Fahrenkrug J (2007) Synaptic contact between melanopsin-containing retinal ganglion cells and rod bipolar cells. Invest Ophthalmol Vis Sci 48:3812-3820.

Perkins KL (2006) Cell-attached voltage-clamp and current-clamp recording and stimulation techniques in brain slices. J Neurosci Methods 154:1-18

Pickard GE, Baver SB, Ogilvie MD, Sollars PJ (2009) Light-induced fos expression in intrinsically photosensitive retinal ganglion cells in melanopsin knockout (opn4) mice. PLoS One 4:e4984.

Schmidt TM, Kofuji P (2009) Functional and morphological differences among intrinsically photosensitive retinal ganglion cells. J Neurosci 29:476-482.

Schmidt TM, Taniguchi K, Kofuji P (2008) Intrinsic and extrinsic light responses in melanopsin-expressing ganglion cells during mouse development. J Neurophysiol 100:371-384.

Slaughter MM, Miller RF (1981) 2-amino-4-phosphonobutyric acid: a new pharmacological tool for retina research. Science 211:182-185.

Viney TJ, Balint K, Hillier D, Siegert S, Boldogkoi Z, Enquist LW, Meister M, Cepko CL, Roska B (2007) Local retinal circuits of melanopsincontaining ganglion cells identified by transsynaptic viral tracing. Curr Biol 17:981-988.

Wang JS, Kefalov VJ (2009) An alternative pathway mediates the mouse and human cone visual cycle. Curr Biol 19:1665-1669.

Wang JS, Estevez ME, Cornwall MC, Kefalov VJ (2009) Intra-retinal visual cycle required for rapid and complete cone dark adaptation. Nat Neurosci 12:295-302.

Warren EJ, Allen CN, Brown RL, Robinson DW (2003) Intrinsic light responses of retinal ganglion cells projecting to the circadian system. Eur J Neurosci 17:1727-1735.

Wässle H (2004) Parallel processing in the mammalian retina. Nat Rev Neurosci 5:747-757.

Wong KY, Dunn FA, Graham DM, Berson DM (2007) Synaptic influences on rat ganglion-cell photoreceptors. J Physiol 582:279-296.

Zaghloul KA, Boahen K, Demb JB (2003) Different circuits for ON and OFF retinal ganglion cells cause different contrast sensitivities. J Neurosci 23: 2645-2654. 